\title{
Infusing Diversity into the Curriculum: What Are Faculty Members Actually Doing?
}

\begin{abstract}
This study was intended as an initial investigation to shed light on how faculty members are implementing multicultural course transformation in their classrooms to prepare students to live and work in a diverse world. We investigated faculty practice as they integrated diversity into the curriculum on a small, regional college campus by conducting a content analysis of faculty annual reports over a five-year period. The vast majority (90\%) of faculty included comments about adding diversity course content, just under half (49\%) included descriptions of different teaching strategies, and a minority talked about better understanding their students (18\%) or themselves (16\%). This article concludes with a discussion of the findings' implications and outlines recommendations for change.
\end{abstract}

Keywords: infusing diversity, curriculum, content analysis, multicultural integration 
Infusing Diversity into the Curriculum: What are Faculty Members Actually Doing?

Virtually every college and university today feels the pressure to prepare students to live and work in a diverse world (Smith \& Wolf-Wendel, 2005). There is a significant body of literature which suggests that serious engagement of diversity in the curriculum, along with linking classroom and out-of-class opportunities, positively affects students' attitudes and awareness about diversity (Smith \& Wolf-Wendel, 2005). Thus, institutions have encouraged and supported faculty efforts in multicultural course change in the general education curriculum and/or in degree programs as they seek to prepare students for a global world. In this study we offer a useful model that suggests that multicultural curriculum transformation involves four key dimensions: course content, pedagogy, students and faculty.

Institutions have been working to diversify the curriculum for a long time. Since 1990, five foundations and a corporate giving program have included curricular and campus climate diversity initiatives among their funding priorities (Orfield, Bachmeier, James, \& Eitle, 1997; McTighe Musil, Garcia, Hudgins, Nettles, Sedlacek, \& Smith, 1999). One example is the Campus Diversity Initiative launched by the Ford Foundation in 1990. They challenged colleges and universities to make diversity the central mission of the educational process. Initially, nineteen campuses received funding for a variety of projects and in half of the institutions the faculty engaged in curriculum reform. Subsequently, between 1990 and 1999, the foundation either directly or indirectly assisted 294 colleges and universities through this initiative, some through direct grants, and others through intermediary organizations. Most Ford Foundation funding was focused on faculty development and curricular innovation. However, external funding is not the only way institutions have moved forward. The vast majority of institutions in the United States have supported diversity initiatives through their own institutional resources, 
motivated by educational, intellectual, and moral imperatives (McTighe Musil et al., 1999). The book, Diversity Across the Curriculum: A Guide for Faculty in Higher Education, presents institutional efforts to transform the curriculum at six different colleges in a variety of majors (Carr, 2007).

Diversifying the curriculum is important on all campuses, but especially those where there is little student and faculty diversity. Justice Sandra Day O'Connor in her response to the Michigan affirmative action case stated, “...numerous studies show that student body diversity promotes learning outcomes, and better prepares students for an increasingly diverse workforce and society, and better prepares them as professionals" (Grutter v. Bollinger, 539 U.S. 306, 2003). Since many students come to campuses from segregated neighborhoods and background (Orfield et al., 1997), it is important that these institutions have a strong commitment to diversifying the curriculum. Campuses that have a primarily white faculty and student population are taking a closer look at how they can better prepare their students for a global world working within the constraints of their demographic makeup. Employers' concerns reaffirm these efforts. In a survey conducted for the Association of American Colleges and Universities, more that 60 percent of employers polled said recent graduates lacked the skills to succeed in a global economy (Fischer, 2007). Specifically they believed that students need an understanding of other cultures, economies, and political systems to be successful. Last year the Committee for Economic Development, a nonprofit group of business and academic leaders, noted that demand for graduates with strong international skills was outstripping supply (Fischer, 2007).

Institutions have chosen to diversify the curriculum because research shows that it does have an impact on student learning. In a longitudinal study of 4,403 college students attending nine public universities it was reported that students who have an opportunity to take a 
diversified curriculum by the second year of college scored higher on 19 of 25 outcomes of the study. The strongest effects of diversity courses were evident on complex thinking skills, retention, cultural awareness, interest in social issues, the importance of creating social awareness, and support for institutional diversity initiatives. Students who took an integrated curriculum also were likely to believe that racial inequality is still a problem and less likely to accept that some social inequity is acceptable in society. These students expressed more interest in poverty, in the importance of making a civic contribution, concern for the public good, support for race-based initiatives, and tolerance for lesbian, gay, and bisexual people. Students who took diversity courses also were more likely to vote in federal or state elections. These results suggest that campus efforts to integrate the curriculum, or adopt a diversity requirement, have far reaching effects on a host of educational outcomes that prepare students as participants in a diverse democracy (Hurtado, 2005).

\section{Implementing Curriculum Changes}

There are different curricular models emerging as campuses diversify the curriculum. Some institutions are adding a diversity requirement; some are focusing on general education programs while others are integrating it throughout the curriculum. At other institutions faculty are adding diversity content to their individual courses or integrating community service projects where students interact with diverse people or concepts (McTighe Musil et al., 1999). In a recent analysis by the Association of American Colleges and Universities of the final self-evaluation reports from the ninety-two institutions in its curriculum and faculty development network, more than half the schools in the project had implemented a diversity requirement (McTighe Musil et al., 1999). Carr (2007) reports that there has been a strong call for change in general education courses especially threshold courses that impact incoming students. In addition, change has 
occurred in professional fields like nursing and social work, under pressure from the professional organizations. Fields like the physical sciences have seemed more resistant to diversity work. As a result, students face a gap in the curriculum and a contradiction because diversity issues are seen as crucial in some parts of the curriculum, but not in others. Thus, students may not get an infusion of diversity and equity across the curriculum (Carr, 2007). The evaluation of the thirty schools in the Lilly Project, Improving Racial and Ethnic Diversity and Campus Climate at Four-Year Independent Midwest Colleges, revealed that no single curriculum model works for all institutions. Curricular transformation can be done using a variety of approaches listed above (McTighe Musil et al., 1999).

As faculty members begin their curricular revisions, they too have many choices. Marchesani and Adams (1992) suggest that faculty embrace a multicultural teaching model that includes four integrated areas: the curriculum, pedagogy, and the attitudes, perceptions, and beliefs of teachers and students. Carr (2007) in her article, "Diversity and Disciplinary Practices," argues that much of the revision work done by faculty has been limited to revising and adding content in courses rather than attending to all four factors. In addition, Carr noted that the diversity "agenda" has been primarily articulated by experts in humanities and social sciences - women's studies, black and ethnic studies, sociology of education, and feminist psychology. The diversity effort has most successfully addressed issues of "diversity" topics such as discrimination, identity, access, power, authority, sexuality, and race.

Banks (1995) agrees with Carr's assessment and argues that many university professors have a limited view of multicultural education, viewing it primarily as curriculum change that includes content about women, and ethnic and other cultural groups. He notes that this perception of multicultural education is widespread because curriculum reform was the main 
focus when the movement first emerged in the 1960s and 1970s and because the popular media has focused on curriculum reform and largely ignored other dimensions and components of multicultural education.

\section{Model}

We utilized the Marchesani and Adams (1992) multicultural teaching model, which was adapted from Jackson (1988) as a framework for our analysis. The model contains four dimensions of the dynamics of diversity in the teaching-learning process: Faculty, Teaching Methods, Course Content, and Students. The model presents a way for faculty to organize the complicated ingredients in the diversity teaching learning process. The Faculty dimension includes knowing oneself, being aware of one's past socialization, and examining one's beliefs, attitudes, and assumptions. Teaching Methods looks at how we teach, broadening teaching strategies to address multiple learning styles, and developing classroom norms that emphasize respect, fairness and equity. The Course Content includes what we teach in a curriculum of inclusion that represents diverse perspectives. The fourth dimension represents the Students and understanding who they are, being sensitive to their various social and cultural backgrounds and the different ways in which they experience the classroom environment. These four dimensions provided a simple typography for classification purposes and formed the basis for our analysis.

$$
\text { Methodology }
$$

\section{Setting Context}

This study was intended as an initial investigation to shed light on what faculty members are actually doing in their classrooms to prepare students to live and work in a diverse world. In response to the challenge to infuse diversity, our small, regional university implemented a change in the faculty members' annual report form. The campus with 3,000 commuter students 
supports the teaching mission with an average of 75 full-time teaching faculty members and numerous adjunct faculty.

Each faculty member was required to include in their annual self-assessment of their teaching a summary of their teaching and curriculum development efforts with respect to diversity. (The exact wording was, "Summarize your teaching and curriculum development efforts on issues relative to diversity.") The goal of the institution was to bring heightened awareness to the need to infuse diversity and equity into the curriculum by adding it to the annual review process. The required faculty annual report statements from six schools within the university: Arts and Sciences, Business, Education, Nursing, Allied Health, and Public and Environmental Affairs, were examined over a five-year period (2003-2007). The pool of faculty participants included all teaching faculty members present at the institution during this five-year span. Names were removed from all reports to ensure anonymity. We conducted a content analysis of each diversity statement.

\section{Operational Definitions}

We utilized the Marchesani and Adams (1992) four-dimensional multicultural teaching model, which was described above, as a framework for our analysis. In order to analyze the faculty diversity statements from their annual reports, we needed an operational definition of each dimension to organize and summarize the data. Course Content $(\mathrm{C})$ refers to what was taught in the curriculum. We looked for topics or issues that reflected a range of perspectives based on race, ethnicity, age, gender, sex, religion, culture or social class. Teaching Methods (T) focused on how the material was taught, so we looked for teaching strategies that would address different learning styles. We specifically looked for methods that went beyond traditional lectures and assigned readings to include collaborative and experiential learning activities. For 
the Faculty dimension (F), we looked for reflective comments describing difficulties faculty members experienced, analysis of their own experiences, attitudes or beliefs, and statements reflecting efforts to improve through diversity workshops or other training. For the final element on Students (S), we looked for discussion of the various social and cultural backgrounds of the students and sensitivity to their different learning styles and unique needs.

\section{Method of Content Analysis}

Three researchers separately read and categorized the faculty statements using a common rubric with the four dimensions defined as above. Each reviewer independently judged whether the faculty statements best fit the Course Content (C), Teaching Methods (T), Faculty (F), or Student (S) dimension. If appropriate, more than one dimension or no dimension was assigned to each statement.

Afterwards, the three researchers compared their categorization of the annual reports. There was a high level of consistency, with complete agreement of all three reviewers in $75 \%$ of the faculty statements. The remaining statements were discussed until a consensus about the appropriate categorization could be reached. The data below reflects the combined consensus of the three researchers.

\section{Limitations}

There are obvious strengths and challenges in this type of ex post analysis of faculty annual reports. First, the prompt given to the faculty was vague and open ended. This meant that the faculty had the opportunity to expound on the diversity elements that they thought were the most important, rather than on a narrow focus from a more specific question. However, this could be seen as a limitation if faculty were uncertain of what to write about. A second observation is that faculty may not have discussed their own attitudes, perceptions, or beliefs 
related to diversity on an employment evaluation instrument. However, it is interesting to note that there were faculty members who did. A final limitation is that there is no way to validate if faculty claims reflect their actual behavior. It should be noted that the annual report is the official university vehicle for faculty to document their activities. Because the faculty member statements were analyzed in this study without names or other identifiers, there were limited follow-up mechanisms (e.g., surveys, interviews) available. These limitations provide opportunities for future research.

\section{Examples of the Four Dimensions}

The majority of faculty referred to specific topics or issues covered in their curriculum that provided a range of perspectives. Differences based on race, ethnicity, age, gender, sex, religion, culture, handicap and social class were all included. Some topics given as examples of Course Content were international trade, international law, cultural and social differences in business practices, human rights, discrimination, affirmative action, diversity in the work place, mental illness, racism, major world religions, Hispanic culture and health care, literature from the Middle East, music from around the world, hate crimes, immigration, public health issues, human development, cross cultural psychology, global environmental issues, intercultural communication, sexual orientation, slavery, folklore, minority literature, comparative politics, and gender issues.

About one half of the faculty described Teaching Methods that deviated from traditional lectures and assigned readings. Examples of strategies included small-group assignments, case studies, team-based learning, service-learning projects, videos, personal stories, guest speakers, field trips to museums, interaction with foreign exchange students, demonstrations, films, and foreign travel. Several faculty members described how these activities addressed different 
learning styles. Examples included, "I incorporated team-based learning to assist students with diverse learning styles," and "I provided modifications in testing for individuals with special needs."

A smaller number of faculty included reflective comments about understanding themselves. Examples of statements included under the Faculty dimension were, "Having lived and worked in Russia and Europe, I draw on my personal and professional experiences for classroom examples," "I consciously broke out of the frankly Western Eurocentric standard format," and "I find it difficult to incorporate diversity topics into technology classes. I am learning through the Diversity Network that even though course content might not lend itself to discussing diversity issues, there is much to learn about teaching and learning styles." Several faculty members listed various international and diversity workshops and other training sessions that they had attended.

A minority of faculty discussed the different ways in which students from different social and cultural backgrounds experience the classroom environment. Some representative examples of the Student dimension were, "I recognize that each student starts their journey of learning at a unique point on their own path," "I try to draw students out who are from different backgrounds," and "Some students who are from other countries had trouble taking notes in class."

\section{Data Analysis}

While the campus has an average of 75 teaching faculty, the percentages shown in the following tables were based on the total faculty who responded to the diversity question on their annual reports. Only $11 \%$ of the total faculty required to submit an annual report did not respond to this diversity question, reflecting a very high overall response rate. 
[Insert Table 1 here]

The first Table showing the combined results for all faculty that responded indicates that the vast majority of faculty (90\%) included comments about course content in their curriculum; one half of the faculty (49\%) included descriptions of different teaching strategies; and a minority of faculty talked about better understanding their students (18\%) or themselves $(16 \%)$. Most of the faculty (86\%) had only one or two dimensions in their diversity statements, and less than two percent of the statements included all four dimensions. Percentages did not vary much from year to year, and many of the faculty (80\%) repeated the same statement for at least two years in a row. Statements even reappeared with the same spelling and grammar mistakes in them.

The remaining Tables show that these same general trends are consistent across all academic units. The vast majority of faculty referred to specific topics or issues covered in their curriculum, about half described flexible teaching strategies, and a minority of faculty included reflective comments about understanding themselves or their students.

[Insert Tables 2, 3, 4, \& 5 here]

Faculty members in Education had the largest number of comments about both content $(100 \%)$ and teaching methods $(71 \%)$. Nursing faculty members had the least number of comments on content (74\%) and the most number of reflective comments (31\%) about both their students and themselves. The faculty members in the Sciences had the highest percentage of faculty $(66 \%)$ that mentioned only one dimension, which was usually content. Business faculty had proportionately more reflective comments about themselves (24\%) than about their students 
(9\%). In contrast, Arts \& Science faculty had more reflective comments concerning students (17\%) and less about themselves (7\%), while Nursing and Education faculty members had equal numbers of reflective comments for both faculty and students.

Discussion on the Four Dimensions of the Model

\section{Course Content}

Faculty members were most likely to include diversity elements through their course content affirming the work of Carr (2007) and Banks (1995). This was perceived by faculty as the most obvious way to satisfy the diversity requirement on their faculty service reports. The most common types of diversity mentioned were race, ethnicity, socioeconomic class, gender, religion and disability. A broad range of topics was included with no real emphasis on any one type of issue.

Some faculty addressed diversity and equity in their content because, by definition, their academic area lends itself to the study of these areas. For example, a faculty member in social and behavioral sciences noted, "this course easily lends itself to multiple aspects of diversity." Another sociology faculty member said, "due to the subject matter, all of my courses reflect topics and issues that explore diversity." A humanities faculty member noted that, "Folklore materials by their very nature lend themselves to diversity." Other faculty members strove to infuse diversity and equity into their courses. A science faculty member commented that, "some of my students are curious about Indian culture. In explaining a math concept, sometimes I give a real world math problem in India." Another faculty member noted, "Diversity is addressed throughout my public speaking course. Students are taught how to speak to a multicultural audience." A faculty member in accounting stated, "My efforts regarding diversity stress the role 
of diverse cultures and nations and how this impacts the setting of accounting standards around the world."

Some faculty wrote broad general statements about their diversity efforts while other faculty reported very specific efforts to infuse diversity and equity into the curriculum. An example of the general approach is one faculty member who reported, "I cover topics of diversity in all of my classes in which it is relevant and appropriate." One other faculty member noted, "My efforts to embrace diversity in the classroom can be seen in the examples I use in class." Other faculty reported very specifically on the topics, readings, and activities they used to infuse diversity. For example, one faculty member in communications noted, "I organized the final exam around the 'Control Room', which is a documentary about Western and Al Jazeera coverage of the Iraqi war." Another faculty member noted, "I took students to the Kinsey Institute and incorporated materials about sexual orientation into the class."

\section{Teaching Methods}

Teaching Methods focused on how the material was taught, so we looked for teaching strategies that would address different learning styles. We specifically looked for methods that went beyond traditional lectures and assigned readings to include collaborative and experiential learning activities. Examples of strategies included small-group assignments, case studies, teambased learning, service-learning projects, videos, personal stories, guest speakers, field trips to museums, interaction with foreign exchange students, demonstrations, films, and foreign travel. A sample comment was, "The service component places students in the community in unfamiliar settings, rich in cultural and racial diversity."

Overall, almost half of the faculty (49\%) addressed pedagogical strategies in their annual reports. This was no surprise as most faculty members are comfortable dealing with content and 
pedagogy in curriculum revision. A higher percentage (71\%) of the faculty members in the School of Education developed pedagogical strategies to address diversity issues, probably because of the nature of their discipline. The most frequently mentioned teaching methods mentioned were case studies, films, small-group discussions, team projects, and guest speakers. Less frequently mentioned were interaction with exchange students, foreign travel, field trips, and service learning projects.

It was encouraging to note that a large percentage of faculty addressed pedagogy in their annual reports. According to Kuh and Whitt (1988), many college faculty members teach the way they were taught and thereby replicate unexamined teaching practices. In addition, Marchesani and Adams (1992) argue that effective multicultural teaching depends on the teacher's dispositions and attitudes to develop a range of teaching strategies.

\section{Faculty}

The faculty dimension includes knowing yourself, being aware of your past socialization, and examining your beliefs, attitudes, and assumptions. For the Faculty dimension, we looked for reflective comments about understanding themselves, referring to difficulties that they have encountered, their personal and professional experiences, and developmental efforts that they have made. A representative comment was, "I am Chinese myself and I understood my students' difficulty, since I had the same experience when I first came to the United States."

It is unfortunate that only a minority of faculty included reflective comments about understanding themselves. As Marchesani and Adams (1992) note, "As a society we are only one generation removed from legally sanctioned educational segregation, and many faculty grew up or are currently living in mono-cultural home, educational, and community environments" (p. 13). They urge faculty to focus thoughtful attention on their own beliefs and attitudes and 
become more aware of the impact of their socialization and learned beliefs on their interactions with students whose social and cultural backgrounds differ from our own. Wlodkowski and Ginsberg (2003), who studied cultural diversity, noted that instructor judgments made when assessing learners are subject to subtle forms of bias that impact student motivation. For example, there may be a tendency for faculty to reward white male students who appear attentive and assertive during class. Chester, Wilson and Milani (1993) conducted 15 focus groups with undergraduate students of color. Several important themes emerged: 1) faculty tended to have low expectations for students of color; 2) the curriculum and classroom interaction often excluded students of color; and 3) classroom structures and pedagogical approaches were limited.

\section{Students}

For the final element on Students, we looked for discussion of how students from various social and cultural backgrounds experience the classroom environment, and reflection on their different learning styles and unique needs. Unfortunately only $18 \%$ of the faculty members reported that they reflected on student diversity issues in their classrooms. Perhaps this is because, in higher education, understanding who our students are is clearly not something that most faculty have been trained to do, nor are they comfortable in doing this type of analysis.

The student dimension holds tremendous potential for improving teaching and learning in a diverse and multicultural environment. Some of the most powerful faculty statements were reflections on efforts to better understand their students. These comments have the most potential to stimulate real change in the culture. Examples included, "An Honors student did a paper on homosexuality and gave a presentation in which the student 'came out' to the class," and "One of my students made a comment on her evaluation form that she did not think I related well to her 
because she was African American. I thought she was just shy, but she perceived that I was not interested in her."

Understanding our students goes far deeper than just focusing on their different learning styles, which has dominated the literature. We need to understand how their different social, economic and cultural backgrounds influence their experiences in their classroom. Additional research and faculty development are needed in this area.

\section{Recommendations}

This study was intended as an initial investigation to shed light on how faculty members are implementing multicultural course transformation in their classrooms to prepare students to live and work in a diverse world. As a pioneering effort, we now have a snapshot of their selfreported diversity activities using the four dimensions of a multicultural teaching model as a framework. The high overall response rate confirmed that the faculty are sensitive to diversity issues and have created courses with multicultural course content. The next step in the research process would be to look at what faculty are doing as they transform their courses, a specific examination of strategies, themes, and pedagogies. According to Cohn and Mullenix (2007), "a diversity rich curriculum: 1) Includes other voices - the focus is on the inclusion of writings, speeches, dialogues, films, etc. that originate from people of different social identities, cultural backgrounds, gender, and disabilities; 2) Communicates interconnectedness - the development of a sense that we are connected to others beyond our immediate experience and geographic area; 3) Values diversity and equity - embeds information and techniques designed to impart a sense of why diversity and equity are important; and 4) Promotes transformative thinking - challenges traditional views and assumptions; encourages new ways of thinking; and re-conceptualizes the field in light of new knowledge, scholarship, and new ways of knowing" (p.13). Surveys and 
interviews could be used to validate these initial findings and help confirm what faculty members actually do in their courses and classrooms to develop a diversity rich course.

Institutions have options available to them as they seek to transform the curriculum within their institutions to prepare students to live and work in a global world. Some campuses have focused on faculty development, others have sponsored summer seminars so faculty can study the scholarship of diversity, and others have sought diversity grants to increase diversity activities (McTighe Musil et al., 1999). A limitation of using the annual report as a vehicle of change is that some faculty members view it as a summative measure and so it limits its effectiveness as a developmental tool. In this study we saw very little growth in faculty efforts over time. For example, if they added content, they were likely to only continue to add content and ignore pedagogy or other elements of diversity. Clearly feedback statements need to include both summative and formative comments, so that faculty members can assess their progress in diversifying the curriculum while also outlining their areas for future development and growth. Aggregating and sharing campus data could help to develop workshops on thematic challenges throughout the institution. The annual report alone does not appear to generate sustained institutional change. The literature shows that the most successful diversity curriculum revision initiatives, "engage people in reading, thinking, and debating over time in a sustained group that fosters development of collegial and personal relationships" (McTighe Musil et al., 1999, p. 25). Future research needs to explore how the annual reporting process can be paired with faculty development efforts to achieve change. Encouraging faculty to discuss their diversity efforts on the annual report allows faculty to see that the campus values diversity, provides an entry point for faculty to discuss their work, and provides an opportunity to receive recognition for their efforts. However, it does not appear to be a vehicle that fosters sustained development. 
Faculty who engage in curriculum transformation need to understand that effective curriculum development in this area is tied to faculty development. Since faculty members typically are already familiar with their individual area of expertise, they need an opportunity to learn the developing scholarship of diversity in order to understand the complexity of teaching diverse students. As the multicultural teaching model enumerates, effective teaching is grounded in the interrelationships among the four components of curriculum, pedagogy, student and teacher. A review of campus diversity efforts revealed that faculty members who engaged in diversity curriculum development efforts reported that it reinvigorated their intellectual life and helped them change their courses, their areas of research, and their relationships with colleagues. In addition, they were more confident teachers and took more risks with interactive and group projects (McTighe Musil et al., 1999). In addition, faculty members need to learn how to assess their efforts to determine if they are enhancing their students' ability to live and work in a global world. While some assessment research has been done, more is needed in relationship to the strategies, themes and pedagogies used in the classroom. 


\section{References}

Banks, J. (1995). Multicultural education: historical development, dimensions, and practice. In J. B. Banks (Ed.), Handbook of research on multicultural education (pp. 3-24). New York, New York: Macmillan Publishing.

Carr, J. F. (2007). Diversity and disciplinary practices. In J. Branche, J. Mullennix, \& E. Cohn (Eds.), Diversity across the curriculum: A guide for faculty in higher education (pp. 3037). Bolton, Massachusetts: Anker Publishing.

Chang, M. (2002). The impact of an undergraduate diversity course requirement on students' racial views and attitudes. Journal of General Education, 25, 125-140.

Chester, M., Wilson, M., \& Milani, A. (1993). Perceptions of faculty behavior by students of color. The Michigan Journal of Political Science, 16, 54-79.

Cohn, E., \& Mullenix, J. (2007). Diversity as an integral component of college curriculum. In J. Branche, J. Mullennix, \& E. Cohn (Eds.), Diversity across the curriculum: A guide for faculty in higher education (pp. 11-17). Bolton, Massachusetts: Anker.

Fischer, K. (2007, November 2). "Flat world" lessons for real-world students. Chronicle of Higher Education.

Frey, B. (2007). Practices that facilitate diversity across the curriculum: Inclusive classroom assessment. In J. Branche, J. Mullennix, \& E. Cohn (Eds.), Diversity across the curriculum: A guide for faculty in higher education (pp. 23-29). Bolton, Massachusetts: Anker.

Gottredson, N., Panter, A., Daye, C., Wightman, L. A., \& Deo, M. (2008). Does diversity at undergraduate institutions influence student outcomes. Journal of Diversity in Higher Education, 1(2), 80-94.

Gurin, P., Dey, E., Hurtado, S., \& Gurin, G. (2002). Diversity and higher education: Theory and impact on education outcomes. Harvard Educational Review, 72 (3), 320-366. 
Hurtado, S. (2005). The next generation of diversity and intergroup relations research. Journal of Social Issues, 61(3), 595-610.

Jackson, B. (1988, October). A model for teaching to diversity. Unpublished paper from a workshop at University of Massachusetts, Amherst.

Kuh, G. D., \& Whitt, E. J. (1988). The invisible tapestry: Culture in american colleges and universities. ASHE-ERIC Higher Education Reports. Washington: Association for the Study of Higher Education.

Marchesani, L. S., \& Adams, M. (1992). Dynamics of diversity in the teaching-learning process: A faculty development model for analysis and action. In M. Adams (Ed.), Promoting diversity in college classrooms (Vol. 52).

McTighe Musil, C., Garcia, M., Hudgins, C., Nettles, M., Sedlacek, \& Smith, D. (1999). To form a more perfect union. Washington: Association of American Colleges and Universities.

Opinion of the Court. (2003). Grutter v. Bolinger, 539 U. S. 306. The U. S. Supreme Court.

Orfield, G., Bachmeier, M., James, D., \& Eitle, T. (1997). Deepening segregation in american public schools: A special report from the harvard project on school desegregation. Equity and Excellence in Education, 30 (2), 5-24.

Shaw, E. (2005). Researching the educational benefits of diversity. New York: College Entrance Examination Board.

Smith, D., \& Wolf-Wendel, L. (2005). The challenge of diversity: Involvement or alienation in the academy? San Francisco, California: Jossey-Bass.

Wlodkowski, R., \& Ginsberg, M. (2003). Diversity and motivation: Culturally responsive teaching. San Francisco, California: Jossey-Bass. 
Table 1

Combined Table of all Faculty and their responses

\begin{tabular}{|c|c|c|c|c|c|c|}
\hline $\begin{array}{l}\text { Number of faculty reporting diversity } \\
\text { experiences in... }\end{array}$ & 2003 & 2004 & 2005 & 2006 & 2007 & Total \\
\hline Content & $\begin{array}{c}43 \\
(87.8 \%)\end{array}$ & $\begin{array}{c}45 \\
(91.8 \%)\end{array}$ & $\begin{array}{c}46 \\
(90.2 \%)\end{array}$ & $\begin{array}{c}52 \\
(88.1 \%)\end{array}$ & $\begin{array}{c}57 \\
(91.9 \%)\end{array}$ & $\begin{array}{c}243 \\
(90.0 \%)\end{array}$ \\
\hline Teaching Methods & $\begin{array}{c}22 \\
(44.9 \%)\end{array}$ & $\begin{array}{c}27 \\
(55.1 \%)\end{array}$ & $\begin{array}{c}24 \\
(47.1 \%)\end{array}$ & $\begin{array}{c}32 \\
(54.2 \%)\end{array}$ & $\begin{array}{c}27 \\
(43.5 \%)\end{array}$ & $\begin{array}{c}132 \\
(48.9 \%)\end{array}$ \\
\hline Faculty reflections on themselves & $\begin{array}{c}10 \\
(20.4 \%)\end{array}$ & $\begin{array}{c}8 \\
(16.3 \%)\end{array}$ & $\begin{array}{c}7 \\
(13.7 \%)\end{array}$ & $\begin{array}{c}9 \\
(15.3 \%)\end{array}$ & $\begin{array}{c}8 \\
(12.9 \%)\end{array}$ & $\begin{array}{c}42 \\
(15.6 \%)\end{array}$ \\
\hline Reflection on the diversity of students & $\begin{array}{c}9 \\
(18.4 \%)\end{array}$ & $\begin{array}{c}8 \\
(16.3 \%)\end{array}$ & $\begin{array}{c}9 \\
(17.6 \%)\end{array}$ & $\begin{array}{c}12 \\
(20.3 \%)\end{array}$ & $\begin{array}{c}11 \\
(17.7 \%)\end{array}$ & $\begin{array}{c}49 \\
(18.1 \%)\end{array}$ \\
\hline Total Number of Faculty responses & 49 & 49 & 51 & 59 & 62 & 270 \\
\hline
\end{tabular}


Table 2

Table of Arts and Sciences Faculty and their responses

\begin{tabular}{lcccccc}
\hline $\begin{array}{l}\text { Number of faculty reporting diversity } \\
\text { experiences in. . }\end{array}$ & 2003 & 2004 & 2005 & 2006 & 2007 & Total \\
\hline Content & 23 & 26 & 26 & 28 & 31 & 134 \\
& $(85.2 \%)$ & $(92.9 \%)$ & $(92.9 \%)$ & $(87.5 \%)$ & $(91.2 \%)$ & $(89.9 \%)$ \\
Teaching Methods & 11 & 15 & 10 & 15 & 10 & 61 \\
& $(40.7 \%)$ & $(53.6 \%)$ & $(35.7 \%)$ & $(46.9 \%)$ & $(29.4 \%)$ & $(40.9 \%)$ \\
Faculty reflections on themselves & 2 & 2 & 2 & 2 & 3 & 11 \\
& $(7.4 \%)$ & $(7.1 \%)$ & $(7.1 \%)$ & $(6.3 \%)$ & $(8.8 \%)$ & $(7.4 \%)$ \\
Reflection on the diversity of students & 5 & 4 & 5 & 7 & 5 & 26 \\
& $(18.5 \%)$ & $(14.3 \%)$ & $(17.9 \%)$ & $(21.9 \%)$ & $(14.7 \%)$ & $(17.4 \%)$ \\
Total Number of Faculty responses & 27 & 28 & 28 & 32 & 34 & 149 \\
\end{tabular}


Table 3

Table of Business Faculty and their responses

\begin{tabular}{lcccccc}
\hline $\begin{array}{l}\text { Number of faculty reporting diversity } \\
\text { experiences in. . }\end{array}$ & 2003 & 2004 & 2005 & 2006 & 2007 & Total \\
\hline Content & 11 & 10 & 10 & 10 & 11 & 52 \\
& $(100 \%)$ & $(100 \%)$ & $(90.9 \%)$ & $(90.9 \%)$ & $(100 \%)$ & $(96.3 \%)$ \\
Teaching Methods & 5 & 4 & 5 & 7 & 5 & 26 \\
& $(45.5 \%)$ & $(40.0 \%)$ & $(45.5 \%)$ & $(63.6 \%)$ & $(45.5 \%)$ & $(48.1 \%)$ \\
Faculty reflections on themselves & 4 & 2 & 3 & 2 & 2 & 13 \\
& $(36.4 \%)$ & $(20.0 \%)$ & $(27.3 \%)$ & $(18.2 \%)$ & $(18.2 \%)$ & $(24.1 \%)$ \\
Reflection on the diversity of students & 1 & 1 & 1 & 1 & 1 & 5 \\
& $(9.1 \%)$ & $(10.0 \%)$ & $(9.1 \%)$ & $(9.1 \%)$ & $(9.1 \%)$ & $(9.3 \%)$ \\
Total Number of Faculty responses & 11 & 10 & 11 & 11 & 11 & 54 \\
\hline
\end{tabular}


Table 4

Table of Nursing Faculty and their responses

\begin{tabular}{lccccccc}
\hline $\begin{array}{l}\text { Number of faculty reporting diversity } \\
\text { experiences in. .. }\end{array}$ & 2003 & 2004 & 2005 & 2006 & 2007 & Total \\
\hline Content & 5 & 5 & 5 & 7 & 7 & 29 \\
& $(71.4 \%)$ & $(71.4 \%)$ & $(71.4 \%)$ & $(77.8 \%)$ & $(77.8 \%)$ & $(74.4 \%)$ \\
Teaching Methods & 4 & 5 & 5 & 5 & 6 & 25 \\
& $(57.1 \%)$ & $(71.4 \%)$ & $(71.4 \%)$ & $(55.6 \%)$ & $(66.7 \%)$ & $(64.1 \%)$ \\
Faculty reflections on themselves & 3 & 3 & 1 & 3 & 2 & 12 \\
& $(42.9 \%)$ & $(42.9 \%)$ & $(14.3 \%)$ & $(33.3 \%)$ & $(22.2 \%)$ & $(30.8 \%)$ \\
Reflection on the diversity of students & 2 & 2 & 2 & 3 & 3 & 12 \\
& $(28.6 \%)$ & $(28.6 \%)$ & $(28.6 \%)$ & $(33.3 \%)$ & $(33.3 \%)$ & $(30.8 \%)$ \\
Total Number of Faculty responses & 7 & 7 & 7 & 9 & 9 & 39 \\
\hline
\end{tabular}


Table 5

Table of Education Faculty and their responses

\begin{tabular}{lccccccc}
\hline $\begin{array}{l}\text { Number of faculty reporting diversity } \\
\text { experiences in. . }\end{array}$ & 2003 & 2004 & 2005 & 2006 & 2007 & Total \\
\hline Content & & & & & & \\
& $(100 \%)$ & $(100 \%)$ & $(100 \%)$ & $(100 \%)$ & $(100 \%)$ & $(100 \%)$ \\
Teaching Methods & 2 & 3 & 4 & 5 & 6 & 20 \\
& $(50.0 \%)$ & $(75.0 \%)$ & $(80.0 \%)$ & $(71.4 \%)$ & $(75.0 \%)$ & $(71.4 \%)$ \\
Faculty reflections on themselves & 1 & 1 & 1 & 2 & 1 & 6 \\
& $(25.0 \%)$ & $(25.0 \%)$ & $(20.0 \%)$ & $(28.6 \%)$ & $(12.5 \%)$ & $(21.4 \%)$ \\
Reflection on the diversity of students & 1 & 1 & 1 & 1 & 2 & 6 \\
& $(25.0 \%)$ & $(25.0 \%)$ & $(20.0 \%)$ & $(14.3 \%)$ & $(25.0 \%)$ & $(21.4 \%)$ \\
Total Number of Faculty responses & 4 & 4 & 5 & 7 & 8 & 28 \\
\hline
\end{tabular}

